\title{
Mathematical Model to Evaluate the Effect of Carbon Monoxide Exposure as a Function of Gender, Age and Height
}

\author{
${ }^{1}$ OLUWATUSIN, O; ${ }^{2}$ OROLU, KO; ${ }^{3}$ EKUN, OA; ${ }^{3}$ AKINLOYE, O; ${ }^{* 3}$ OYEDIRAN, AA \\ ${ }^{1}$ Department of Mechanical Engineering, ${ }^{2}$ Department of Systems Engineering, ${ }^{3}$ Department of Medical Laboratory Science, College of \\ Medicine, University of Lagos \\ *Correspondent author Email: ayooyediran@hotmail.com
}

\begin{abstract}
This study develops and solves mathematical models using a time-dependent Fick's law of diffusion with the tools of non-Newtonian mechanics specifically the power-law fluid model with appropriate boundary conditions to predict the concentration profiles of carboxyhemoglobin $(\mathrm{COHb})$ species in the human bloodstream from carbon monoxide (CO) inhaled over some time. The concentration of $\mathrm{CO}$ and the length of exposure determines how much harm it does to the body. The model developed prediction compares favourably with experimental results and other models in the literature. The standard error obtained when compared with the experiment is 1.02. The results show that the height of individuals has a significant effect on $\mathrm{COHb}$ and $\mathrm{CO}$ concentration in both adult male and female such that taller individuals are more susceptible to $\mathrm{CO}$ poisoning than shorter ones, but height has no significant effect in children. Similarly, the male is at a higher risk of CO poisoning than the female counterpart of the same age and height.
\end{abstract}

DOI: $\underline{\text { https://dx.doi.org/10.4314/jasem.v23i5.4 }}$

Copyright: Copyright (C) 2019 Oluwatusin et al. This is an open access article distributed under the Creative Commons Attribution License (CCL), which permits unrestricted use, distribution, and reproduction in any medium, provided the original work is properly cited.

Dates: Received: 20 April 2019; Revised: 17 May 2019; Accepted 23 May 2019

Keywords: $\mathrm{CO}$ poisoning, concentration, exposure time, carboxyhemoglobin

The levels of pollution of the environmental media on this planet namely: air, land, and water bodies are rising daily with an increase in the human population as well as the increasing number of vehicles and electric power plants that release toxic gas emissions into the atmosphere. This poisonous gas, carbon monoxide (CO), is emitted from the exhaust pipes of internal combustion engines of these machines in which a class of fossil fuels namely: Premium Motor Spirit (PMS) and Automotive Gas Oil (AGO) are burnt for vehicular propulsion and electric power generation respectively. This phenomenon is commonly found in congested cities of both developing and developed countries across the globe. Cities with high vehicle density such as Hong Kong (246 vehicles per kilometre) and Berlin (208 vehicles per kilometre), and Lagos (222 vehicles per kilometre) all have a likelihood of Carbon monoxide (CO) pollution (World vehicular emissions Inventory, 2013). The primary consequence is the negative impact on the health of human subjects that are resident or working in these densely-populated cities. $\mathrm{CO}$ is an odourless, tasteless, and colourless gas. It is the second most common environmental pollutant after carbon dioxide (Ruth-Sahd et al., 2011). The environmental $\mathrm{CO}$ level is a function of the ventilation available. Sully et al. (2018) reported that the environmental $\mathrm{CO}$ concentration levels could be as low as $0.02 \%$ if a fire is well ventilated, whereas smouldering, poorly ventilated fires can produce between 1 and $10 \%$ carbon monoxide. Adewunmi (2016) reported that CO constitutes about 5 to $10 \%$ of the exhaust gases from an average automobile or truck engine. $\mathrm{CO}$ poisoning may occur as a result of inhalation of exhaust gas from automobiles, electric power plants, or incomplete combustion of charcoal, briquettes, fuel gas or oil in a closed place (Kudo et al., 2014). The concentration of $\mathrm{CO}$ and the length of exposure determines how much harm it does to the body. Agajo et al. (2011) noted that smaller concentrations could be harmful over a more extended period while increasing concentrations becomes harmful within a shorter period. The symptoms of $\mathrm{CO}$ poisoning are nonspecific and therefore tend to be under-recognised in health care settings (Ruth-Sahd et al., 2011). Haemoglobin has a stronger affinity with $\mathrm{CO}$ than with oxygen up to about 230 times (Bateman, 2003) binding with the haemoglobin in the blood to form carboxyhemoglobin $(\mathrm{COHb})$ in the bloodstream (Modic, 2003). The duration of exposure to $\mathrm{CO}$ determines the classification as acute or chronic poisoning. More prolonged exposure causes a reduction in the oxygen carrying capacity in the tissues resulting in ailments such as headache, dizziness, lightheadedness, memory loss, nausea, vomiting, fatigue, confusion, hallucination, disorientation, visual

*Correspondent author Email: ayooyediran@hotmail.com 
disturbance, seizures and prevalence of death in prolonged exposure to CO (Struttmann et al., 1998). Ruth-Sahd et al. (2011), identified four areas of the pathophysiological effects of CO. These include haemoglobin binding, direct cellular toxicity, protein binding, and increases in nitric oxide (NO). Several researchers have carried out studies on $\mathrm{CO}$ diffusion in human subjects without considering the age, gender and height of the subjects. In most cases, those parameters are considered in isolation. From experiments and hospital records, Ruth-Sahd et al. observed that children have the highest nonfatal rate for $\mathrm{CO}$ exposure, whereas older adults accounted for $23.5 \%$ of COP deaths monitored. However, males are 2.3 times more likely succumb to $\mathrm{CO}$ poisoning than females counterpart. The report further noted that Non-Hispanic whites and African Americans have the highest death rate. This paper, therefore, reports a mathematical model to evaluate the effect of carbon monoxide exposure as a function of gender, age and height.

\section{MATERIALS AND METHOD}

The mechanisms involved in the transport of $\mathrm{COHb}$ in the pulmonary capillary are the molecular convection and the expedited diffusion of $\mathrm{CO}$ due to the presence of haemoglobin as a carrier (figure 1).

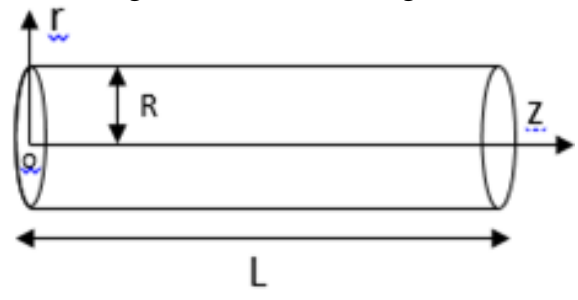

Fig 1. Schematic diagram of the model

We consider the pulmonary capillary as a cylindrical channel. Based on Fick's Law of diffusion for CO and $\mathrm{COHb}$ transport and concentration in the bloodstream, we have the following 1D systems of partial differential equations:

$$
\begin{aligned}
& \frac{\partial C_{C O}}{\partial t}+v \nabla C_{C O}=D_{c o} \nabla^{2} C_{C O}-S \\
& \frac{\partial C_{C O H b}}{\partial t}+v \nabla C_{C O H b}=D_{c o} \nabla^{2} C_{C O H b}+S
\end{aligned}
$$

Where $C_{\mathrm{CO}}$ is the concentration of $\mathrm{CO}, \mathrm{C}_{\mathrm{COHb}}$ is the concentration of $\mathrm{COHb}$ and $S$ is the source term. The source term as derived by Gibson and Roughton (1955) is given as
$S=m^{\prime} \frac{C_{C O}\left(C_{H b}-C_{O_{2 H b}}\right)}{c_{\mathrm{O}_{2}}}-m C_{C O H b}$

Where $m^{\prime}=$ association rate to $\mathrm{CO}$ and $m=$ dissociation rate.

Incorporating the relationship of the diffusion capacity $D_{c o}$ with age, height and gender expressed in Joumard et al. (1981), as

Male Adult:

$D_{c o}=0.329 H-0.000135 Y-0.318$

Female Adult:

$D_{c o}=0.119 H-0.00087 Y-0.015$

Children:

$D_{c o}=0.117 A-0.022$

Development of Power Law Fluid Model: The blood is considered as a pseudo-plastic fluid in which the apparent viscosity decreases with an increase in shear rate. Hence, the axisymmetric blood flow through an axially symmetric circular cylindrical artery is considered to be a power law fluid, and blood flow is steady and laminar with no following reaction in the blood after the formation of $\mathrm{COHb}$. The constitutive relation for a power law fluid pioneered by Ostwaldde Waele (1924) is given as

$\tau_{r z}=-k\left|\left(\frac{d v}{d r}\right)\right|^{n-1} \frac{d v}{d r}$

Where $\tau_{r z}$ is the shear stress, $k=$ power law prefactor usually regarded as a function of temperature and $n=$ Power law exponent, $\frac{d v}{d r}=$ velocity gradient

The shear stress can be expressed as

$\tau_{r z}=\frac{1}{2} \Delta P r$

Where $\Delta P$ is the pressure gradient. Hence, equation (5) becomes

$\frac{d v}{d r}=\left(-\frac{\Delta P r}{2 k}\right)^{\frac{1}{n}}$ 
Considering that the velocity gradient is zero at the centre, while there is no slip at the boundary, the associated boundary conditions are:

$\left\{\begin{array}{lll}\frac{d v}{d r}=0 & \text { at } & \\ v=0 & & r=R\end{array}\right.$

Integrating (7), we have

$v=\int_{0}^{R}\left(-\frac{\Delta P r}{2 k}\right)^{\frac{1}{n}} d r$

(9)

$v(r)=\left(\frac{\Delta P}{2 k}\right)^{\frac{1}{n}}\left(\frac{n}{n+1}\right) r^{\frac{1}{n}+1}$

For a power law fluid such as blood, $0<n<1$

Representing equations (1) and (2) in cylindrical coordinate in a dimensionless form and substituting equation 10 , we have

$\frac{\partial C_{1}}{\partial t}+v \frac{\partial C_{1}}{\partial r}=D\left\{\frac{\partial^{2} C_{1}}{\partial r^{2}}+\frac{1}{r} \frac{\partial C_{1}}{\partial r}\right\}-\beta C_{1}\left(1-C_{2}\right)+\beta C_{2}$

$\frac{\partial C_{2}}{\partial t}+v \frac{\partial C_{2}}{\partial r}=D\left\{\frac{\partial^{2} C_{2}}{\partial r^{2}}+\frac{1}{r} \frac{\partial C_{2}}{\partial r}\right\}+\beta C_{1}\left(1-C_{2}\right)-\beta C_{2}$

Where $\beta=\frac{m^{\prime} \alpha C O}{m \alpha O_{2}}$

$\beta$ is a constant that represents the affinity of haemoglobin for $\mathrm{CO}$ over $\mathrm{O}_{2}$.

The initial and boundary conditions are:

At $t=0, C_{1}=0.76 \% \quad C_{2}=0 . \%$

At $r=0, \frac{\partial C_{1}}{\partial r}=0$ for all $t>0$

At $r=1, \frac{\partial C_{2}}{\partial r}=0$ for all $t>0$

The equations (11) and (12) are solved using the nonlinear PDE module in MATLAB toolbox for cylindrical coordinates in the form

$\left[\begin{array}{l}1 \\ 1\end{array}\right] \bullet * \frac{\partial}{\partial t}\left[\begin{array}{l}C_{1} \\ C_{2}\end{array}\right]=D \frac{\partial}{\partial r}\left[\begin{array}{l}\frac{\partial C_{1}}{\partial r}+\frac{1}{r}-\frac{v}{D} \\ \frac{\partial C_{2}}{\partial r}+\frac{1}{r}-\frac{v}{D}\end{array}\right]-\beta\left[\begin{array}{l}C_{1}\left(1-C_{2}\right)-C_{2} \\ C_{1}\left(C_{2}-1\right)+C_{2}\end{array}\right]$

\section{RESULTS AND DISCUSSION}

Equation 15 is solved with different age and height for male and female as well as children using the parameters in Table 1. The results are compared with the experiment of Peterson and Stewarts(1970) and other models in the literature. The percentage $\mathrm{COHb}$ computed for a male adult of height $1.6 \mathrm{~m}$ and 30 years, of age, is shown in Table 2. The standard error of our model, when compared with the experiment of Peterson and Stewarts (1970), is 1.02. The standard errors for Singh et al. (1991) model, CFK equation and nomogram, when compared with the same experiment are $0.848,1.31$ and 1.56 , respectively. The experiment of Peterson \& Stewarts did not state the specific gender, age and height of the respective subjects. If the gender, age and height of the subjects are available, the likelihood of our model prediction having the least error is high.

Table 1. Simulation parameters

\begin{tabular}{llll}
\hline S/N & $\begin{array}{l}\text { Parameter } \\
\text { Description }\end{array}$ & Symbol & Value \\
\hline a) & $\begin{array}{l}\text { Concentration of } \\
\text { Haemoglobin }\end{array}$ & $\mathrm{Hb}$ & $\begin{array}{l}9.302 \times 10^{-6} \\
\mathrm{~mol} / \mathrm{ml}\end{array}$ \\
b) & Radius of Artery & $\mathrm{R}$ & $4 \times 10^{-6} \mathrm{~m}$ \\
c) & Transit Time & $\mathrm{T}$ & $0.75 \mathrm{sec}$. \\
d) & Association Rate & $\mathrm{m}^{\prime}$ & $18.8 / \mathrm{sec}$. \\
e) & Dissociation Rate & $\mathrm{m}$ & $0.062 / \mathrm{sec}$. \\
f) & Power law index & $\mathrm{n}$ & 0.6 \\
\hline
\end{tabular}

Table 2. Comparison of $\mathrm{COHb}$ result of the model with the experiment by Petersons and Stewart (1970)

\begin{tabular}{|c|c|c|c|}
\hline $\begin{array}{l}\text { Ambient } \\
\text { CO }\end{array}$ & $\begin{array}{l}\text { Exposure } \\
\text { Time }\end{array}$ & $\begin{array}{l}\text { Experimental } \\
\text { (Peterson and } \\
\text { Stewarts }(1970))\end{array}$ & $\begin{array}{l}\text { Our } \\
\text { model }\end{array}$ \\
\hline 25.4 & 120 & 1.5 & 1.88 \\
\hline 39.6 & 60 & 1.8 & 1.74 \\
\hline 44.7 & 120 & 2.48 & 2.85 \\
\hline 46 & 180 & 3.86 & 3.79 \\
\hline 48 & 240 & 5.07 & 4.73 \\
\hline 50.2 & 360 & 5.1 & 6.29 \\
\hline 50.3 & 480 & 5.6 & 7.34 \\
\hline 51.2 & 180 & 3.75 & 4.16 \\
\hline 51.5 & 30 & 1.3 & 1.43 \\
\hline 51.6 & 60 & 2.12 & 2.06 \\
\hline 87.9 & 60 & 2.9 & 3.03 \\
\hline 91.9 & 180 & 6.61 & 6.98 \\
\hline 93.2 & 360 & 10.75 & 11.12 \\
\hline 93.5 & 60 & 3.37 & 3.18 \\
\hline 94 & 480 & 12.08 & 13.05 \\
\hline 96.4 & 120 & 5.1 & 5.42 \\
\hline 98.1 & 180 & 7.23 & 7.4 \\
\hline 98.4 & 240 & 7.34 & 9.07 \\
\hline 98.7 & 180 & 6.36 & 7.44 \\
\hline 99 & 120 & 3.96 & 5.54 \\
\hline 99.2 & 180 & 7.02 & 7.48 \\
\hline 99.3 & 30 & 2 & 2.09 \\
\hline 99.7 & 60 & 3.27 & 3.34 \\
\hline 99.8 & 480 & 12.42 & 13.78 \\
\hline 100 & 45 & 3.05 & 2.74 \\
\hline 100.2 & 480 & 12.87 & 13.83 \\
\hline 101 & 360 & 11.38 & 11.97 \\
\hline 101.5 & 360 & 11.27 & 12.03 \\
\hline 102 & 30 & 2.1 & 2.13 \\
\hline 103.2 & 420 & 10.59 & 13.29 \\
\hline 196.9 & 120 & 10.08 & 10.28 \\
\hline 198.4 & 180 & 13.83 & 14.08 \\
\hline 199.5 & 240 & 15.97 & 17.29 \\
\hline 200.8 & 30 & 3.43 & 3.49 \\
\hline 200.8 & 60 & 5.93 & 6.01 \\
\hline 502 & 15 & 5.25 & 4.25 \\
\hline 502 & 90 & 18.4 & 19.19 \\
\hline
\end{tabular}


Effect of Gender on $\mathrm{COHb}$ concentration: Figure 2 shows that the concentration for a male is higher than female. The male is at a higher risk of $\mathrm{CO}$ poisoning than the female counterpart of the same age and height.

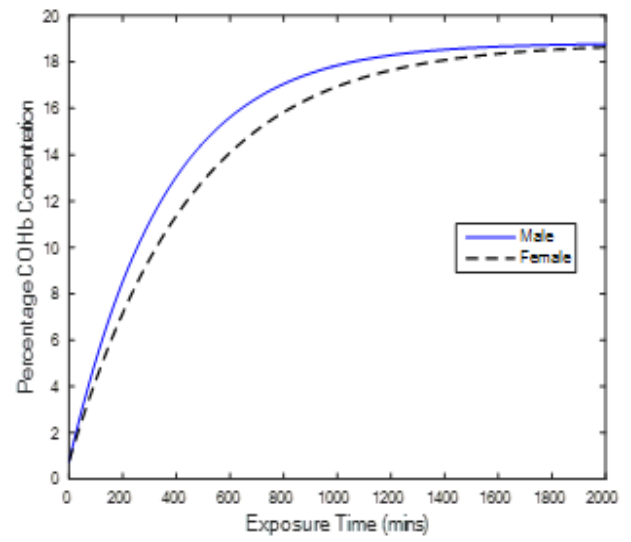

Fig 2: Effect of Gender on $\mathrm{COHb}$ against exposure time for $1.7 \mathrm{~m}$ height and 50 years of age at 100p.p.m ambient CO

Effect of Age on $\mathrm{COHb}$ concentration: There is no significant influence of age difference in the concentration of $\mathrm{CO}$ or $\mathrm{COHb}$ for men. However, there is a significant influence of age difference in the concentration of $\mathrm{COHb}$ in women. The younger women have a higher concentration of $\mathrm{COHb}$ while the older women have a lower concentration when exposed to the same level of $\mathrm{CO}$ as shown in Figure 3.
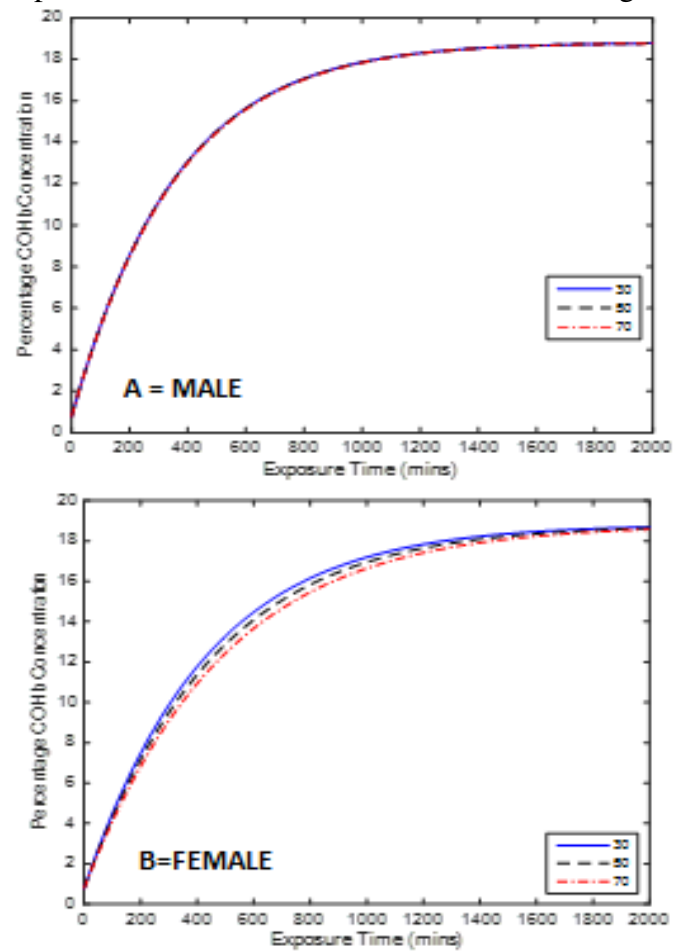

Fig 3. Effect of Age on $\mathrm{COHb}$ Concentration against exposure time for Male and female of height $1.7 \mathrm{~m}$ at 100p.p.m ambient $\mathrm{CO}$
Effect of Height on $\mathrm{COHb}$ concentration: From Figure 4 , the height of individuals has a significant effect on $\mathrm{COHb}$ and $\mathrm{CO}$ concentration in both male and female. The concentration is higher in taller human than in shorter ones and takes a longer time in shorter humans to reach steady state.
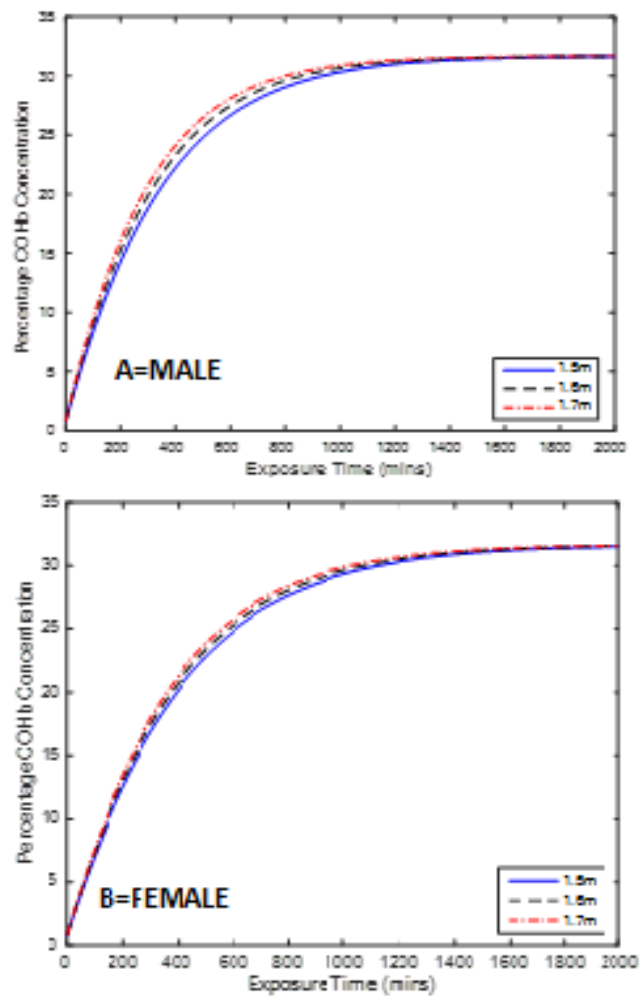

Fig 4. Effect of Height on $\mathrm{COHb}$ Concentration against exposure time for Male and female of 50 years old at 200p.p.m ambient CO

Effect of Ambient $\mathrm{CO}$ on $\mathrm{COHb}$ concentration: In Figure 5, the level of $\mathrm{CO}$ and $\mathrm{COHb}$ concentration is a function of the level of ambient $\mathrm{CO}$ in the environment. The higher the ambient $\mathrm{CO}$, the higher the percentage $\mathrm{COHb}$. The pattern is similar in both male and female.

Effects of Age on COHb Concentration in Children: The effect of $\mathrm{COHb}$ and $\mathrm{CO}$ concentration are affected by the ages of Children only. Height and gender have no significant effect, unlike adults. The concentration of ambient $\mathrm{CO}$ determines the level of concentration after exposure as shown in figures 6a. However, Figure 6(b) show the effect of age on the concentration of $\mathrm{COHb}$ to exposure time in children. The concentration is higher in older children than in younger ones. The concentration of $\mathrm{CO}$ takes a longer amount of time to reach a steady state in younger children than in older children. 

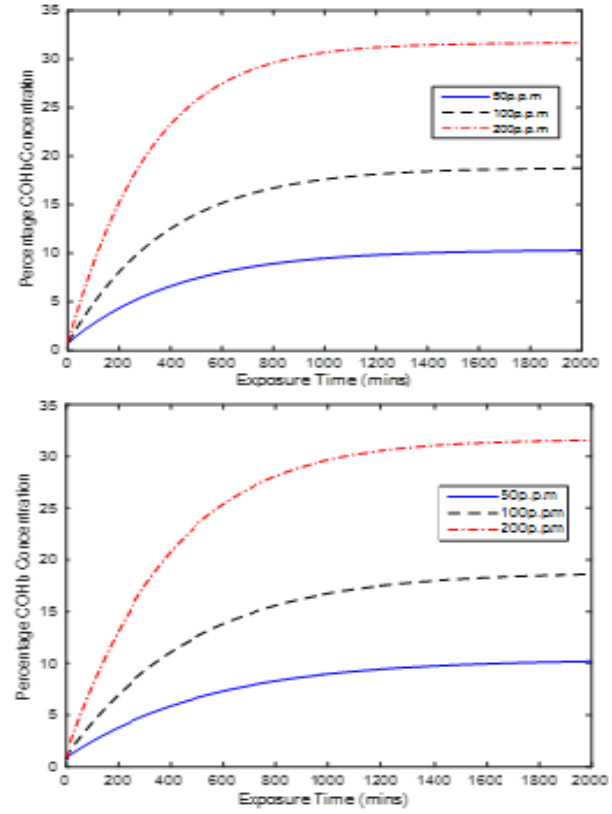

Fig 5. $\mathrm{COHb}$ against exposure time for $1.7 \mathrm{~m}$ height and 50 years of age at for varying ambient $\mathrm{CO}$
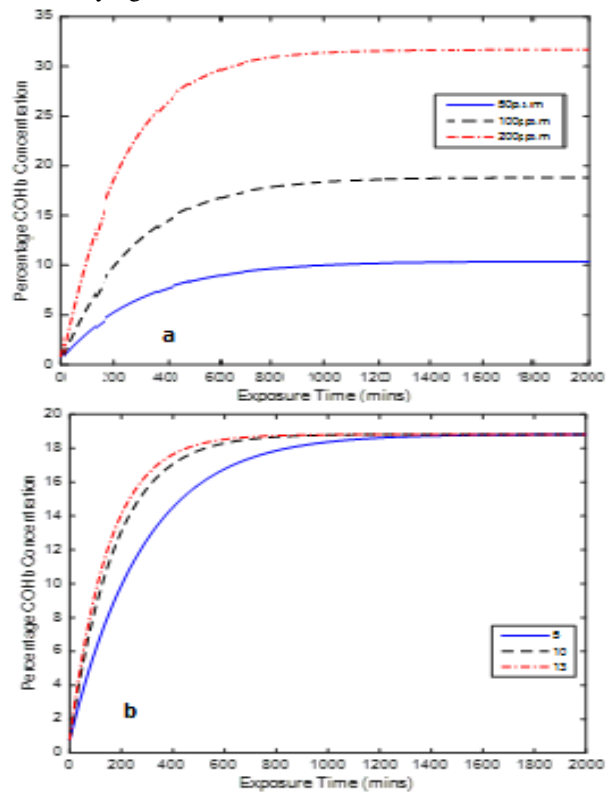

Fig 6. Effect of $\mathrm{COHb}$ on Children (a) 5 years of age at varying ambient CO (b) $100 \mathrm{ppm}$ Ambient $\mathrm{CO}$ at varying Age

Conclusion: In this work, a power-law based model for the prediction of $\mathrm{COHb}$ and $\mathrm{CO}$ concentration in human blood as a function gender, age, height and exposure time has been developed. The results show that the height of individuals has a significant effect on $\mathrm{COHb}$ and $\mathrm{CO}$ concentration in both adult male and female such that taller individuals are more susceptible to $\mathrm{CO}$ poisoning than shorter ones. The result is in agreement with experimental work and other models in the literature.

\section{REFERENCES}

Adewunmi T (2016). Determination of Carbon Monoxide Content of Exhaust Gases from Agricultural and Road Transport Tractors in Nigeria: A Case Study of Ogbomoso Metropolis. In 2016 ASABE Annual Int. Meeting (p. 1). Amer Soc of Agric and Bio Engineers.

Agajo, J., Inyiama, HC; Theophilus, AL (2011). Remote Monitoring and Estimation of Carbon Monoxide Pollution in Indoor Environment using Wireless Sensor Network via Satellite. Pacific J. of Sci and Technol, 12(2), 464-479.

Bateman, DN (2003). Carbon Monoxide. Med.31 (10):233.

Gibson, QH; Roughton, FJW (1955). The Kinetics of Dissociation of the First Oxygen Molecule From Fully Saturated Oxyhaemoglobin In Sheep Blood Solutions. Proceedings of the Royal Soc of London. Series B-Bio Sci, 143(912), 310-334.

Joumard, R; Chiron, M; Vidon, R; Maurin, M; Rouzioux, JM (1981). Mathematical Models of The Uptake of Carbon Monoxide on Hemoglobin at Low Carbon Monoxide Levels. Environ Health persp, 41, 277-289

Kudo, K; Otsuka, K; Yagi, J; Sanjo K; Koizumi, N; Koeda, A; Shiga, Y (2014). Predictors For Delayed Encephalopathy Following Acute Carbon Monoxide Poisoning. BMC Emer Med (14)3.

Modic, J (2003). Carbon Monoxide and $\mathrm{COHb}$ Concentration in Blood in Various Circumstances. Energy and Buildings, 35(9), 903-907.

Peterson, JE; Stewart, RD (1970). Absorption and elimination of carbon monoxide by inactive young men. Arch of Environ Health: An Intl J., 21(2), 165171.

Ruth-Sahd, LA; Zulkosky, K; Fetter, ME (2011). Carbon Monoxide Poisoning: Case Studies and Review. Dim of Crit Care Nurs, 30(6), 303-314

Singh, MP; Sharan, M; Selvakumar, S (1991). A Mathematical Model for The Computation of Carboxyhaemoglobin in Human Blood As A Function of Exposure Time. Philosophical Trans of the Roy Soc of Lon. Ser B: Bio Sci, 334(1269), 135-147

Struttmann, T; Scheerer, A; Prince, TS; Goldstein, LA (1998). Unintentional Carbon Monoxide Poisoning From An Unlikely Source. The J. of the Amer Board of Fam Prac, 11(6), 481-484

Sully, CJ; Walker, GS; Langlois, NE (2018). Investigation Into The Potential for Post-Mortem Formation Of Carboxyhemoglobin in Bodies Retrieved From Fires. Forensic Sci, Med and Pathol, 14(3),342-348 